\title{
A equạ̧ão não resolvida do mercado de microfinanças no Brasil
}

CINARA G. DE ARAÚJO LOBO

\section{APRESENTAÇÃO}

$\mathrm{Na}$ teoria econômica clássica, mercado é um conceito que não demanda explicação sobre a sua constituição e funcionamento. É tratado como uma premissa da qual se parte para outras teorizações, como se fosse um conceito evidente que dispensasse qualquer tipo de descrição quanto ao arranjo institucional que o regula. $O$ mercado funciona assim como filtro que seleciona o mais qualificado e eficiente e, em seu aspecto mais prático, comomecanismo de precificação e alocação de recursos. Richard Swedberg (1994) chama a atenção para os poucos estudos existentes na teoria econômica sobre mercado. Localizou apenas um capítulo sobre o assunto, "On Markets", na obra Princípios da Economia de Alfred Marshall. No entanto, mesmo esse autor não tratou mercado como instituição, ele avalia, mas como parte de uma discussão maior, envolvendo demanda, oferta e valor.

Na Sociologia Econômica e mesmo na Economia, crescem atualmente os estudos que conceituam mercado como estrutura social, o que significa dizer que é o resultado de "formas recorrentes e padronizadas de relações entre atores, mantidas por meio de sanções" (Swedberg, 1994:255; ver também Abramovay (2004), Fligstein and Dauter (2007), Powell e DiMaggio (1983, 1999), MEYER and ROWAN (1977); Granovetter (1983, 1985).Tratar mercado como estrutura social implica afastar-se do conceito liberal, que o definia como arena neutra onde compradores e vendedores anônimos e desorganizados, em situações de informação perfeita, disputavam o melhor preço e as melhores condições negociais. $\mathrm{Na}$ visão da Sociologia Econômica, mercados são socialmente e historicamente construídos a partir da interação dos atores, que fixam formas concretas de coordenação, que estabelecem quem tem o direito a participar e em que condições, o 
que é permitido trocar e segundo parâmetros de preço e qualidade definidos nas relações cotidianas. A Sociologia Econômica não para na descrição das restrições formais e informais que regulam as trocas, quer dar conta dos atores e como eles perseguem seus interesses reais em estruturas institucionais concretas.

Dessa forma, mercado é uma arena social, onde recursos escassos são negociados, conforme a habilidade dos atores em fazer valer seus interesses. Abramovay explica que "os mercados só podem ser compreendidos como espaços reais de confronto entre atores, cuja forma depende exatamente da força, da organização, do poder e dos recursos de que dispõe cada parte. A abordagem sociológica dos mercados procura compreendê-los não como premissas da ação econômica, mas como resultados concretos" (Abramovay, 2004: 58).

Por essa razão, o comportamento do mercado deve ser explicado a partir da cultura local, dos padrões de troca desenvolvidos, do marco legal regulatório, do acesso a tecnologias e técnicas legitimadas, das relações de interesse e cooperação, das práticas cotidianas dos atores, enfim, através da configuração de interações e relações sociais que delimita e constrói mercado. Tratar mercado como estrutura social implica dizer que ele possui uma ordem institucional, um conjunto de regras explícitas ou informais que define o seu funcionamento, que estabelece quem pode participar e em que condições.

Neste texto, a proposta é levantar os desafios e entraves ao desenvolvimento do setor de microfinanças no Brasil, tratando-o como estudo de caso para analisar mercado enquanto estrutura social. A experiência brasileira em microfinanças ilustra como, apesar de aparentemente aberto, as regras que regulam mercado podem dificultar o acesso das camadas mais populares aos serviços bancários. A democratização do crédito para a população tradicionalmente excluída do sistema financeiro tem ocorrido lentamente, apesar das mudanças que o governo empreendeu no marco legal e da mobilização dos setores organizados da sociedade, como Igreja, Ongs, Oscips, cooperativas e sociedades de crédito.O mercado de microfinanças começou, no Brasil, nos anos 70, através da UNO (União Nordestina de Assistência a Pequenas Organizações), antes mesmo da criação do Grameen Bank de Bangladesh e das primeiras experiências nos países da América Latina (cf. Marulanda, 2006), mas seus resultados ainda são tímidos, apesar da demanda, estimada em 14 milhões de pessoas (Soares e Sobrinho, 2008:26). 
Não existem pesquisas que tragam números exatos sobre a dimensão da demanda por microcrédito nos setores mais populares da economia, mas levantamento feito pelo Ministério do Trabalho e Emprego (MTE) exemplifica a carência do setor (Cf. ANTEAG, 2006). O órgão contabilizou, em 2007, 21.859Empreendimentos de Economia Solidária ${ }^{86}$ (EES) espalhados por 2.933 municípios. Essas organizações concentravam-se, principalmente, na região Nordeste $(43,5 \%)$ e reuniam 1,6 milhão de participantes. Apesar de serem empreendimentos coletivos, organizados como associação (52\%), grupos informais (36,5\%), cooperativas (10\%) e outras formas $(1,5 \%), 56 \%$ das entidades entrevistadas declararam o acesso ao crédito como uma das dificuldades para manter e expandir o negócio e 76,4\% disseram necessitar de financiamento. A maioria dos EES $(65 \%)$ havia iniciado suas atividades usando recursos próprios. A segunda fonte vinha de doações (22\%) e somente 13\% tiveram acesso a empréstimos. Entre aqueles que tiveram acesso a crédito nos últimos 12 meses, ou seja, 3,4 mil empreendimentos, pouco mais da metade (57\%) conseguiu em bancos públicos e apenas $6 \%$ em bancos privados.

Pelos números do MTE, observa-se que há uma demanda reprimida por crédito nos setores produtivos mais populares, e que a maioria continua sem acesso a linhas formais de financiamento e serviços financeiros. $O$ que não se justifica principalmente no caso dos EES que já possuem faturamento médio mensal, indicador de maturidade do empreendimento. Segundo a pesquisa do MTE, dos 15.101 EES que declararam faturamento superior a zero, a média mensal correspondia a $\mathrm{R} \$ 43.232,67$. Ao estratificar por faixas, verificou-se que na menor faixa (até $R \$ 1.000,00$ ) estavam 3.628 empreendimentos com faturamento médio mensal de $R \$ 520,54$. A segunda faixa compreendia aqueles com rendimento entre $R \$ 1.001,00$ a $R \$ 5.000,00$ e reunia 35,83\% dos EES que ganhavam, em média, $\mathrm{R} \$ 2.492,46$ por mês.

Observa-se, portanto, que o crédito não chega ao setor informal da economia ou naqueles empreendimentos que não possuem volume de faturamento. Nem os bancos públicos nem os bancos privados mostram-se eficientes em prover crédito para os nanoempreendimentos. A hipótese que será trabalhada neste texto é a de que o arranjo

\footnotetext{
${ }^{86}$ Empreendimento de Economia Solidária compreende um "conjunto de atividades econômicas - de produção, distribuição, consumo, prestação de serviços, poupança e crédito - organizadas e realizadas solidariamente por trabalhadores e trabalhadoras sob a forma coletiva e autogestionária" (ANTEAG, 2009: 17). Para ser enquadrado como economia solidária, o empreendimento deve ter cooperação e solidariedade entre os membros, autogestão e agregação de esforços para viabilizar iniciativas coletivas de produção.
} 
institucional existente contribui para manter de fora do mercado financeiro os setores populares da economia. A inclusão desse público impulsionaria o desenvolvimento econômico do país e somaria para diminuir índices de pobreza. Os ganhos iriam além do público diretamente beneficiado e alcançariam o conjunto da sociedade.

Douglas North (2004) ressaltou a importância das instituições para explicar desempenho econômico. Diferenças no padrão de desenvolvimento entre os países podem ser consequência dos arranjos institucionais que se formaram no decorrer da história. Embora as instituições contribuam para reduzir incertezas e gerar previsibilidade e confiança nas relações de trocas entre os atores, nem sempre os resultados são positivos. Instituições também podem perpetuar comportamento sub-ótimo do mercado.

Douglas North explica que "instituições não são necessariamente criadas para serem socialmente eficientes; em vez disso, elas, e no mínimo as regras formais, são criadas para servir aos interesses desses com poder de barganha para tramar novas regras" (North, 2004: 16). Se houve economias que obtiveram ganhos comerciais ao criar instituições relativamente eficientes, argumenta que isso ocorreu porque "sob certas circunstâncias os objetivos privados destes com poder de barganha alteraram as instituições produzindo soluções institucionais que se mostraram socialmente eficientes ou que se desenvolveram nesse sentido" (idem).

Assim como arranjo institucional é importante para compreender estágios diferentes de desenvolvimento entre os países, também é uma variável que ajuda a explicar o funcionamento dos mercados. Não se trata de procurar pela vontade deliberada dos atores que dificultaria o desenvolvimento de mercados, mas sim pelas normas jurídicas, que impedem a entrada e o fortalecimento de novos atores com capacidade e interesse em prover serviço financeiro para o segmento de menor renda, no caso, ao mesmo tempo, em que atuam favorecendo outros atores que não têm interesse em modificar as atuais regras do jogo.

O funcionamento do mercado tem implicações não apenas sobre o desenvolvimento econômico, mas também sobre o modo como se distribui a riqueza na sociedade. Para Amartya Sen (2010), a pobreza não é consequência do pleno desenvolvimento dos mercados e da capacidade maior ou menor dos indivíduos em realizarem seus interesses privados, mas decorre, entre outros fatores, da dificuldade de acesso dos mais pobres ao mercado econômico. "A negação do acesso ao mercado de 
produtos frequentemente está entre as privações enfrentadas por muitos pequenos agricultores e sofridos produtores sujeitos à organização e restrições tradicionais. $A$ liberdade de participar do intercâmbio econômico tem um papel básico na vida social" (Sen, 2010: 21). As restrições ao funcionamento dos mercados reforçam privilégios e impedem o exercício de liberdades por parte dos pobres.

A carência de serviços financeiros para o segmento de baixa renda não se justifica diante da estrutura do sistema financeiro brasileiro, considerado sólido e com avançado nível tecnológico. Em 2011, as 16 principais instituições financeiras que operam no Brasil somaram US\$ 9,95 bilhões em investimentos em tecnologia, a frente de economias como Austrália (US\$ 5,69 bilhões), México (US\$ 3,40 bilhões) e Índia (US\$ 3,90 bilhões) ${ }^{87}$. Sua robustez ficou demonstrada na crise financeira global de 2008 e reafirmou-se, recentemente, na que atingiu a Europa, quando as instituições financeiras do país ficaram praticamente imunes ao choque. No País não foram registrados casos de falência, tampouco houve socorro do governo às instituições, por meio de aporte de recursos, como ocorreu em outras economias. Outro dado que também serve para avaliar a solidez do sistema financeiro brasileiro é o Índice de Basiléia (Acordo de Basiléia do Bank of International Settlements), que traz indicadores da solvência de uma instituição. A média das instituições brasileiras foi de $16 \%$ no final de 2011 , cinco pontos percentuais acima do nível mínimo de $11 \%$ recomendado pelo Banco Central do Brasil e oito pontos além dos $8 \%$ estabelecidos pelo acordo.

O sistema bancário nacional conta, ainda, com rede de atendimento dotada de ampla capilaridade, o que facilitaria expandir a oferta de serviços de microfinanças e democratizar o acesso ao crédito. Hoje, todos os municípios brasileiros possuem algum tipo de atendimento financeiro, seja por meio de agências, correspondentes ou postos bancários avançados. A extensão geográfica do país e o isolamento de alguns municípios não são fatores que dificultam ou impedem a oferta de crédito e a bancarização da população de baixa renda.

Por que, então, os bancos não desenvolvem serviços para quem não tem renda comprovada? Por que ainda não encontraram tecnologia bancária eficiente para realizar análise de crédito e gestão de carteira para o segmento de menor renda? Qual o motivo

87 Dados retirados da pesquisa "Ciab Febraban 2012 _ O Setor Bancário em Números", in http://www.febraban.org.br/Noticias1.asp?id texto=1591, consulta realizada em 20/08/2012. 
para o setor de microfinanças não alcançar ritmo e escala condizentes com as dimensões do país?

A forte estrutura e a solidez do sistema bancário nacional levam a procurar respostas para o problema da microfinanças no Brasil nas instituições que regulam o seu funcionamento. Não é possível tratar o tema sem investigar as razões que tornam o atual marco regulatório excludente, os interesses que impedem os ajustes necessários e a visão dos atores sobre a problemática da microfinanças. A proposta do texto será explorar essas variáveis, ao invés de repetir as interpretações correntes que problematizaram o assunto a partir do desenvolvimento de novas tecnologias de análise de crédito, carência de capital social e organização do público interessado.

\section{OS MODELOS DE MICROFINANÇAS NO BRASIL}

No Brasil, é possível identificar duas estratégias distintas de microcrédito: a desenvolvida pelo governo de Fernando Henrique Cardoso (1999-2002) e a que será depois adotada a partir do governo de Luiz Inácio Lula da Silva (2003). Enquanto a primeira estruturou um sistema financeiro paralelo para ofertar crédito a microempreendedores, a última passou a demandar dos bancos que realizassem esse tipo de operação. As duas experiências se diferem quanto a quem foi dado o papel de protagonista da política de microcrédito: as instituições de microfinanças ou os bancos tradicionais. Em comum mantiveram a distância entre esses organismos financeiros e 0 ordenamento jurídico que impediria a transformação do primeiro no segundo.

Até 1994, praticamente, não existiam organizações especializadas em microcrédito no Brasil. Operavam apenas a Rede CEAPE e o Banco da Mulher, associado ao Banco Mundial da Mulher. Após a estabilização econômica, apareceram as primeiras instituições de microfinanças (IMF). Governos municipais e estaduais criaram os bancos populares e passaram a prestar apoio a ONGs. Em 1996, o BNDES lançou o Programa de Crédito Produtivo Popular para financiar as organizações existentes e, em 1998, o Banco do Nordeste iniciou o Programa CrediAmigo.

A revisão do marco legal e a estruturação de um sistema institucional próprio para o mercado de microfinanças, no Brasil, tiveram início a partir de 1999. A Lei 9.790/1999 abriu para a ONG de microcrédito a possibilidade de atuar qualificada como Organização 
da Sociedade Civil de Interesse Público (Oscip) e sem obrigatoriedade de se submeter à Lei da Usura, que limitava a operar com juros de no máximo $12 \%$ ao ano. Em seguida, foram expedidas duas Medidas Provisórias ( $n$ ํ 1.914 e 1.894) que estabeleceram as linhas gerais da atividade e regulamentou a Sociedade de Crédito ao Microempreendedor (SCM).

O Conselho do Programa Comunidade Solidária foi responsável por mobilizar entidades governamentais e não governamentais para implantar e desenvolver estratégia de microcrédito no País.A estrutura desenhada pelo governo federal dividia-se em dois pisos. O primeiro bloco era formado por instituições que atuavam diretamente com 0 cliente final. Nela estavam incluídas: organizações da sociedade civil (Oscips), instituições do setor público (Banco do Nordeste, bancos de desenvolvimento dos estados e os bancos populares dos governos municipais e estaduais) e instituições da iniciativa privada (Sociedade de Crédito ao Microempreendedor - SCMs). O segundo bloco reunia as instituições denominadas de segunda linha, responsáveis por dar capacitação, apoio técnico e proverem as primeiras de recursos financeiros. Nele estavam o BNDES, através do Programa de Crédito Popular/PCPP e do Programa de Desenvolvimento Institucional/PDI, além do Sebrae, com o Programa Sebrae de Microcrédito.

Portanto, havia três categorias de iniciativas de microcrédito no Brasil: as desenvolvidas pela sociedade civil (organizações não governamentais, sem fins lucrativos), pelo Poder Público (programas diversos de instituições de "primeira" e "segunda" linhas); e pela iniciativa privada (com fins lucrativos, SCMs). Entre os bancos comerciais, sejam eles públicos ou privados, apenas o Banco do Nordeste trabalhava com o programa CrediAmigo. Verfica-se que, no sistema institucional desenhado para o microcrédito, os bancos não foram chamados a participar diretamente com a oferta de crédito à população de baixa renda. Em lugar dos bancos, foram criadas as SCM - nova figura jurídica de direito privado, voltada exclusivamente para a concessão do microcrédito e que só podia funcionar com autorização e sob a supervisão do Banco Central do Brasil.

Apesar do status de principal instituição de microfinanças do mercado nacional, a SCM nasceu com limitações legais que a impedia de expandir de seus serviços, tais como:

a) Não podia atuar como correspondente bancário; 
b) Possuía limitado fundings para suas operações de crédito;

c) A atuação restringia-se à região definida no estatuto social;

d) Estava expressamente vedada a conceder empréstimos para fins de consumo;

e) Não poderia contratar depósitos interfinanceiros como depositante ou depositária;

f) O endividamento estava limitado a, no máximo, cinco vezes o respectivo patrimônio líquido;

g) Diversificação de risco de crédito por cliente poderia ser de no máximo $\mathrm{R} \$ 10$ mil;

h) Estava impedida de captar, sob qualquer forma, recursos junto ao público, bem como emitir títulos e valores mobiliários destinados à colocação e oferta públicas.

As reivindicações que os representantes das SCM levaram ao governo federal, durante a "Rodada de Interlocução Política" - evento promovido pelo Conselho da Comunidade Solidária, em 2001 - exemplificavam as dificuldades que encontravam em superar as barreiras legais ao funcionamentoe estabelecer trocas comerciais com o sistema bancário tradicional. Também indicam a preocupação constante do governo em impedir a contaminação desse sistema com o que se formava em torno das operações de microcrédito.

Dessa Rodada resultaram várias modificações na política adotada e para as SCM significou a aprovação da Resolução CMN 2.874, de 26 de julho de 2001, que flexibilizou suas condições de trabalho. Permitiu a SCM ser controlada por Oscip, atuar em todo território nacional, tomar empréstimos junto ao Sistema Financeiro Nacional, vender sua carteira de crédito para as demais instituições financeiras, aplicar a disponibilidade de caixa em operações de CDB e RDB e instalar Postos de Atendimento ao Microcrédito (PAM). Mas essas mudanças não foram suficientes para garantir condição de pleno funcionamento para as SCMs, que continuaram a reclamar de outras limitações legais que as impediam de expandir a carteira de crédito, ou ofertar outros produtos financeiros além do microcrédito, ou mesmo diversificar os riscos das operações de crédito, emprestando para clientes fora do perfil de menor renda. Continuava em vigor a exigência deno mínimo $\mathrm{R} \$ 100 \mathrm{mil}^{88}$ como capital realizado e patrimônio líquido para uma SCM funcionar. Seu endividamento estava restrito a cinco vezes o respectivo patrimônio

\footnotetext{
${ }^{88}$ Os valores baixos de capital mínimo possibilitavam pequenas iniciativas, mas não garantiam o sucesso e a perenidade do empreendimento, já que o volume de crédito a ser emprestado estava limitado a cinco vezes o patrimônio líquido.
} 
líquido, podendo emprestar até $\mathrm{R} \$ 10$ mil por cliente e vedados os empréstimos para consumo e habitação.

O microcrédito na gestão do presidente Fernando Henrique Cardoso era uma política importante de trabalho e renda e de combate à pobreza e à exclusão social, mas que deveria ser desenvolvida por organizações civis fossem com fins lucrativos ou não. Não era visto como estratégia de curto prazo para fortalecer mercado interno e incentivar o consumo, como mais tarde será tratado pelo governo de Luís Inácio Lula da Silva, mas sim como uma estrutura que se desenvolveria a longo prazo, sem envolver o sistema bancário tradicional. Ao Estado caberia dar apoio, treinamento gerencial e prover fundings para as operações, conforme descreve o texto da cartilha publicada pelo Programa Comunidade Solidária:

\begin{abstract}
"Cabe ao Estado, não só atuar em parceria para apoiar ações da sociedade civil nas áreas de capacitação, tecnologia e informação, mas sobretudo apoiar ações da sociedade civil focalizadas de (sic.) construção de Centros de Referência de Microcrédito em regiões compostas por municípios de pequeno porte onde estão sendo induzidos processos de DLIS - Desenvolvimento Local Integrado e Sustentável - e onde o capital financeiro privado dificilmente chegará" (Barone, Lima, Dantas e Rezende, 2002:7)
\end{abstract}

É preciso ponderar que, naquele momento, já era uma novidade o envolvimento do governo federal com o setor de microcrédito, pois, até então, esse era um assunto restrito às Ongs, aos organismos internacionais financiadores, e às prefeituras e aos governos estaduais, que começaram a empreender iniciativas isoladas. Somente, a partir de 1999, o executivo chama para si a tarefa de estruturar o setor, definindo um marco legal e convocando entidades públicas a contribuir. No entanto, permanecia a compreensão de que aquela não era uma atividade de bancos comerciais. O próprio Banco do Nordeste agia como simples repassador de recursos, quem realmente operacionalizava 0 CrediAmigo era o Instituto Nordeste Cidadania - até hoje a entidade responsável.

Tanto era essa a compreensão, que na XVI Reunião do Conselho da Comunidade Solidária, que aconteceu em 25 de agosto de 1997, retirou-se como consenso básico que o microcrédito só iria se expandir e cumprir com seu papel estratégico no campo das políticas de trabalho e renda se fosse tratado "de forma diferenciada do crédito tradicional" (Brasil, 2002:7).

Os resultados do primeiro modelo de política de microcrédito implantado no Brasil ficaram abaixo das expectativas. Em 2002, havia 37 SCM, sendo 26 ativas e 11 
autorizadas a funcionar pelo Bacen. A maioria concentrava-se na região Sudeste, o que significava uma baixa cobertura geográfica pelo País. Juntas reuniam $R \$ 10,8$ milhões em operações de crédito e $\mathrm{R} \$ 14,6$ milhões em ativos, o que correspondia a 0,001\% dos ativos totais do Sistema Financeiro Brasileiro ${ }^{89}$. Cartilha do Programa Comunidade Solidária reconhecia que os resultados alcançados até então eram mínimos frente à demanda:

\begin{abstract}
"Não obstante, ainda são muitos os desafios para a verdadeira consolidação de uma indústria microfinanceira no País: a oferta ainda é reduzida frente à demanda; o número de instituições, programas, operações e recursos envolvidos ainda são pequenos face às necessidades de um país continental com uma população que ainda apresenta milhões de pessoas em situação de pobreza; o microcrédito rural ainda é incipiente; o apoio ao primeiro negócio ainda é irrisório; as instituições de microcrédito ainda são frágeis do ponto de vista gerencial etc" (Barone, Lima, Dantas e Rezende, 2002:5).
\end{abstract}

O conselheiro e membro do Comitê Executivo da Comunidade Solidária, Augusto Franco, alegava que as Ongs microfinanceiras, qualificadas como Oscips pelo Ministério da Justiça, e as SCM enfrentavam problemas de gestão. Demonstravam pouco conhecimento das estratégias de mercado e do sistema de informação contábil, operacional e gerencial, além de ser baixa a produtividade dos agentes de crédito. Tudo isso, impedia o desenvolvimento do setor (Cf. Comunidade Solidária, 2002:8).

A partir de 2003, a estratégia de microcrédito se modifica, deixa de ser uma política específica de desenvolvimento social e passa a ser um componente na política econômica do governo federal. O assunto sai da pasta do Programa Comunidade Solidária e vai para o âmbito do Ministério da Fazenda num indicador claro de que o tema não mais era abordado pelo viés social, mas tornava-se ferramenta de política econômica, com a tarefa de democratizar o acesso ao crédito e, assim, fortalecer mercado interno e fomentar o crescimento da economia. Microcrédito, associado a outras medidas econômicas de estímulo ao crédito e bancarização, deveria acirrar a concorrência no setor bancário e pressionar para a redução dos juros, ao mesmo tempo em que incentivaria o aumento do consumo.

O jornal O Estado de São Paulo publica matéria com o então ministro da Fazenda, Antônio Palocci, onde relata a expectativa do governo quanto os efeitos do pacote de medidas lançado em junho de 2003:

\footnotetext{
${ }^{89}$ Cf. Relatório de Evolução do SFN, Bacen, 2011. Disponível em http://www.bcb.gov.br/?REVSFN201112
} 
"Segundo ele, o conjunto de medidas já adotadas pelo governo tem permitido a redução dos juros em todo o mercado. Entre essas medidas, Palocci citou o programa de incentivo ao microcrédito, que começou a funcionar esse mês. 'Já há redução de juros em todo o mercado e a redução dos juros no consumo básico. Esse conjunto de medidas certamente vai trazer um crescimento da economia', afirmou" (Estado de S. Paulo, 26 agosto de 2003, Microcrédito já provoca efeitos positivos, diz Palocci).

O pacote de microcrédito, editado naquele ano, incluía a massificação das contas simplificadas (Res. Bacen n.3.104 de 25/06/2003 e 3.113 de 31/07/2003), a destinação de $2 \%$ dos recursos do recolhimento compulsório sobre os depósitos à vista para operações de microcrédito (Lei n. 10.735, de 11/09/2003), a flexibilização da legislação para a formação de cooperativas de crédito de livre associação (Res. Bacen 3.106 de 25/06/2003), aumento do número de correspondentes bancários e dos serviços prestados (Res. Bacen n. 3.110 de 31/07/2003 e 3.156 de 17/12/2003), regulamentação do crédito consignado (Lei 10.820 de 17/12/2003) e constituição do Banco Popular do Brasil (MP 121, de 25 de junho de 2003) - subsidiária do Banco do Brasil, que iria atuar exclusivamente com a população de baixa renda no setor de microfinanças. Tais alterações no marco legal deveriam levar a dois processos que se somariam: a bancarização da população excluída do sistema financeiro e a popularização do acesso ao crédito, não importava para o governo, naquele momento,se o incentivo iria para o crédito destinado ao consumo ou para produção, embora o volume de recursos contratados fosse maior no primeiro.

Para o microcrédito produzir os resultados que o governo federal esperava precisava ganhar escala. A experiência acumulada, até então, indicava que o ritmo e o volume dos empréstimos concedidos pelas IMFs seriam insuficientes para responder às expectativas. Por essa razão, as medidas editadas pela equipe econômica voltam-se para o sistema bancário tradicional e, principalmente, para os bancos públicos. Não é por acaso que pela primeira vez se emprega o termo "microfinanças" na legislação brasileira. A expressão aparece na Medida Provisória 121, de junho de 2003, que autorizou o Banco do Brasil a criar o Banco Popular:

"I - Um banco múltiplo, com o objetivo de atuação especializada em microfinanças, consideradas estas o conjunto de produtos e serviços financeiros destinados à população de baixa renda, inclusive por meio de abertura de crédito a pessoas físicas de baixa renda e microempresários, com ou sem comprovação de renda; (...)" (grifo nosso) 
Como as Oscips e SCMs estavam impedidas de oferecer outros produtos bancários além do microcrédito, não fazia sentido falar em microfinanças. Seus clientes não poderiam usufruir de serviços como contas correntes, poupanças, cartões de crédito, seguros e outros. Mesmo que tivessem acesso ao crédito, não chegariam a integrar o sistema financeiro no status de correntistas ${ }^{90}$.Somente quando os bancos passaram a participar da estratégia de democratização do crédito fez sentido falar em microfinanças.

As alterações na legislação não abriram novos mercados para as Oscips e SCM, que continuaram restritas a ofertar crédito para o setor produtivo. Entretanto, o novo governo buscou aumentar o funding para suas operações na expectativa de que assim impulsionaria o setor. A Medida Provisória n. 122 de 2003 (Resolução 3.109 de 2003), que determinou à aplicação de $2 \%$ dos depósitos à vista em operações de microcrédito, autorizou os bancos privados e públicos a repassar recursos a outros bancos e SCMs. Tanto poderiam emprestá-los diretamente ao tomador final ou destiná-los a operações intermediadas por SCM, além de ficarem autorizados a adquirir carteira de crédito de SCM, Oscips e Ongs ${ }^{91}$. Outro funding para as operações das SCMs veio do FAT, as instituições que operavam com recursos do Fundo puderam repassá-los às IMFs para operações com microcrédito.

No entanto, a aplicação dos recursos provenientes de $2 \%$ dos depósitos à vista foi direcionada principalmente para o consumo, o que levou o governo federal a publicar a MP n. 226, em novembro de 2004, convertida em Lei n. 11.110, de 25 de abril de 2005, criando o Programa Nacional de Microcrédito Produtivo e Orientado (PNMPO). Para corrigir a aplicação dos recursos, o governo define critérios específicos no uso dos depósitos à vista das instituições bancárias e autoriza a cobrar juros mais altos, de $2 \%$ a $4 \%$, reconhecendo que a operacionalização do microcrédito exigiria atendimento diferenciado. "Essa última modalidade de crédito apresenta maior custo, sendo em geral intermediada por um agente de crédito e necessitando de tecnologia específica" (Ministério da Fazenda, 2004: 63). Também eleva o valor que poderia ser emprestado (de

\footnotetext{
${ }^{90}$ Esse é um atributo importante, pois a história financeira do cliente, ou seja, seu cadastro, o auxilia a migrar quando preferir para outra instituição financeira, a transferir operações de crédito e a ampliar limite de crédito.

91 A resolução da CMN 2.109/03 estabeleceu o DIM (Depósito Interfinanceiro vinculado a Operações de Microfinanças) que foi acessível somente pelo Banco do Nordeste. Não há notícias de que tenha sido usado por outas IMFs, tais como Oscips e SCM (Cf. MTE, 2008:55)
} 
$\mathrm{R} \$ 1$ mil para $\mathrm{R} \$ 5 \mathrm{mil})$, beneficiando microempreendedores com renda bruta anual de até $\mathrm{R} \$ 60 \mathrm{mil} / \mathrm{ano}$ ou $\mathrm{R} \$ 5 \mathrm{mil} / \mathrm{mês}$.

A regulamentação da legislação do PNMPO foi entendida pelas entidades representativas das IMFs como excessiva e restritiva às suas atividades. " $A$ sobreregulamentação contida nesses instrumentos legais constrange o aumento do fluxo esperado de recursos e dificulta o acesso dos operadores aos fundos do setor financeiro público ou privado" (Pereira, Mross, Alves, Aguiar, 2009:88). Reclamavam contra a fixação de valores máximos de empréstimos,limitação da renda do tomador de crédito e tabelamento das taxas de juros.

Pesquisa realizada pela Associação Brasileira das Sociedades de Crédito ao Microempreendedor e à Empresa de Pequeno Porte (ABSCM), em 2006, indicava que os principais entraves ao desenvolvimento das SCMS eram: o impedimento de atender às empresas de pequeno porte e o limite de risco de crédito por cliente, fixado em $\mathrm{R} \$ 10$ mil. A entidade dizia que a conjunção desses dois fatores gerava um engessamento da instituição que comprometia o seu crescimento e a obtenção de resultados mínimos que tornassem o negócio atrativo. Reivindicavam que o governo, ao direcionar o crédito para os empreendimentos de muito pequeno porte, atuasse não nas normas estruturantes das SCMs, mas sim nas linhas de crédito que serviriam ao setor. Em outras palavras, as limitações do governo não deveriam incidir sobre as atividades das SCMs, mas sim sobre as linhas voltadas para microcrédito. As restrições à atuação das SCMs terminavam inviabilizando suas operações (Cf. Neto e Pinto, 2007).

$\mathrm{Na}$ queda de braço entre governo e IMFs novas alterações foram feitas na legislação. A Lei 11.524, de 2007, modificou a Lei n. 10.194, de 2001, inserindo a empresa de pequeno porte no rol do público-alvo das SCMs e não apenas as microempresas. Passaram assim a serem chamadas de SCMEPPs (Sociedade de Crédito do Microempreendedor e à Empresa de Pequeno Porte). A Resolução n. 3.567 de 2008 removeu o limite de risco de crédito de $\mathrm{R} \$ 10$ mil por cliente e fixou em $5 \%$ do patrimônio líquido, ajustado pelas contas do resultado.

Desse modo, paulatinamente, foram sendo revistos os impedimentos legais ao funcionamento das SCMEPP sem, contudo, colocá-las em condições semelhantes às instituições bancárias. As mudanças feitas na legislação não conseguiram impulsionar os negócios das SCMEPPs, tanto que elas diminuíram sua participação no SFN nos últimos 
anos. Conforme descreve o gráfico 1, eram 56 organizações, em 2006 e passaram para 42, em 201192. Estima-se que o mesmo venha acontecendo com as Oscips. Pesquisa realizada pelo Sebrae, constatou que das 152 instituições cadastradas no Ministério do Trabalho e Emprego para operarem com o PNMPO, apenas 103 continuavam em atividade sete anos depois (Cf. Sebrae, 2011).

Gráfico 1. Evolução do número de SCM, 2001- 2011

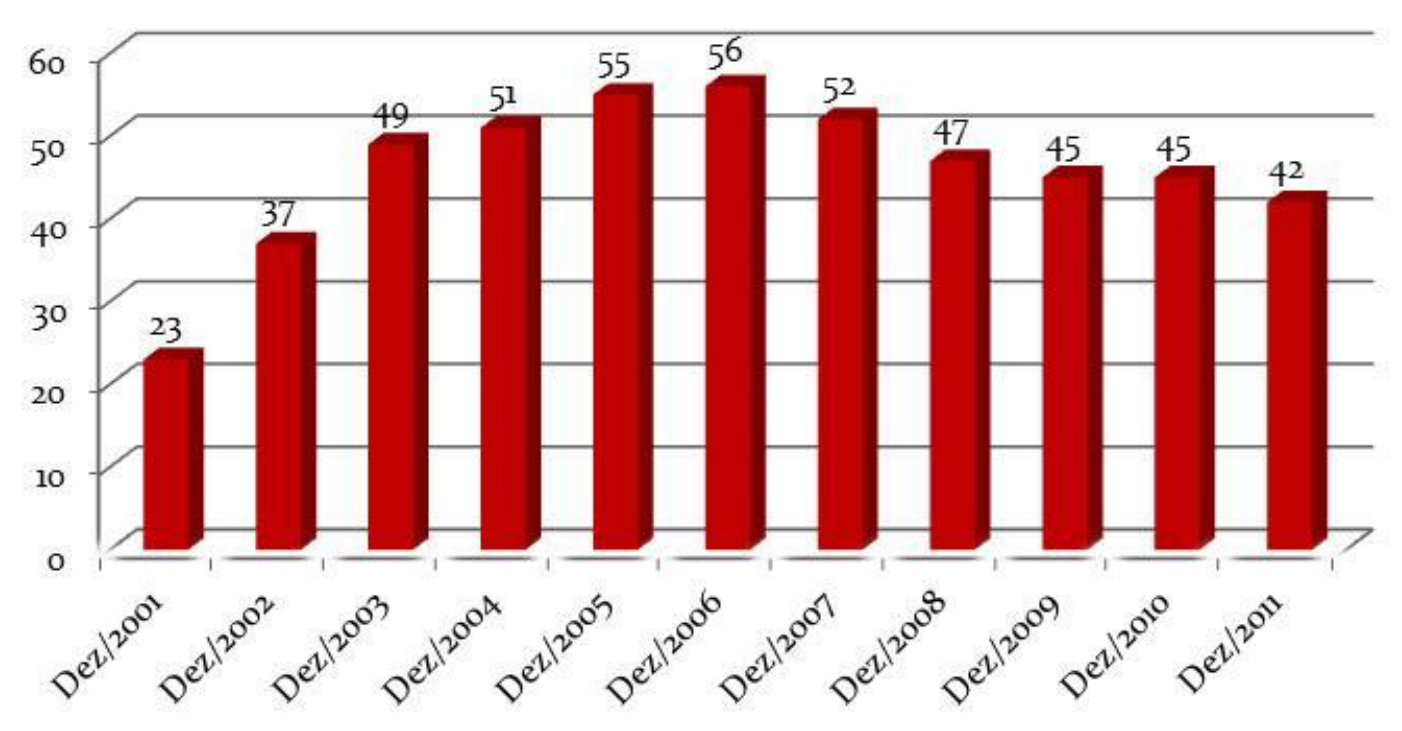

Fonte: Bacen

O governo federal esperava que, ao aumentar o funding para as operações de crédito realizadas pelas IMFs e ampliar o limite de empréstimo com o qual trabalhavam, as medidas adotadas fossem suficientes para garantir maior participação dessas entidades no mercado. Não considerou a possibilidade de que o problema talvez estivesse na estruturação das IMFs e nos impedimentos legais à expansão de seus serviços, tais como: possibilidade de captar depósitos, de estabelecer juros conforme as particularidades da região e dos tomadores, de diversificar portfólio de produtos, enfim, de evoluir para bancos de varejo especializados em microfinanças. O governo contou que haveria divisão de papéis entre bancos e IMFs: os primeiros responsáveis por garantir o

\footnotetext{
${ }^{92}$ Cf. Relatório de Evolução do SFN, Bacen, 2011. Disponível em http://www.bcb.gov.br/?REVSFN201112.
} 
retorno do capital público direcionado para as linhas de microcrédito e as últimas com o trabalho de ir até o cliente, emprestar e acompanhar os empreendimentos financiados.

\section{COMPARAÇÃO COM A AMÉRICA LATINA}

Mas o fato é que apesar de todas as mudanças no marco legal que regulamenta as operações de microfinanças, o governo federal ainda não conseguiu garantir o acesso da população mais pobre ao crédito, condições sustentáveis de funcionamento para as IMFs, tampouco ampliou a participação do sistema bancário tradicional. Quantidade elevada dos depósitos compulsórios, que deveria ir para operações de microcrédito, continua sendo recolhida pelo Banco Central numa clara demonstração que os bancos não encontram viabilidade operacional e financeira. Em dezembro de 2011, conforme dados do Banco Central, foram direcionados $\mathrm{R} \$ 156,44$ milhões em operações de microcrédito voltadas para o consumo e $\mathrm{R} \$ 497,24$ para o setor produtivo, num total de $\mathrm{R} \$ 653,68$ milhões. No entanto, a lei exigia a aplicação de $\mathrm{R} \$ 3,7$ bilhões.

O próprio governo federal reconhece que permanece parcela da população sem acesso ao crédito e a serviços financeiros, que poderiam ajudá-la a mudar sua situação social. No programa Brasil Sem Miséria, que pretende elevar a renda daqueles em situação de extrema pobreza, o Ministério do Desenvolvimento Social (MDS) identifica a microfinanças como ferramenta estratégica para promover inclusão social ${ }^{93}$. Calcula, a partir de dados do IBGE (Instituto Brasileiro de Geografia e Estatística), que 16,27 milhões de pessoas ou $8,5 \%$ da população brasileira vive em situação de extrema pobreza, em domicílios com renda igual ou menor que $\mathrm{R} \$ 70,00$. Para atingir esse público, o governo baixou a taxa de juros, de 60\% para $8 \%$ ao ano, subsidiando parte dos serviços financeiros. Não houve alterações na legislação em relação às IMFs com o Programa Crescer, que é parte do Brasil Sem Miséria.

No primeiro mandato de Luiz Inácio Lula da Silva, o governo imaginava, numa visão otimista, que os $2 \%$ dos depósitos a vista direcionados para operações de microcrédito seriam totalmente empregados e contribuiriam não apenas para geração de emprego e renda, como também incentivariam os bancos a reduzir taxas de juros. Mas a

\footnotetext{
${ }^{93}$ Ministério do Desenvolvimento Social e Combate a Fome,Plano Brasil Sem Miséria. Disponível em http://www.brasilsemmiseria.gov.br/. Acesso em 02/09/2012.
} 
reação foi inesperada, os bancos preferiram não ser remunerados pelos depósitos a emprestar. A situação do Brasil é ainda mais controversa, quando comparada a outros países da América Latina onde a estrutura bancária é bem mais frágil e a economia mais fraca.

Conforme o gráfico 2,verifica-se que a carteira de microcrédito do Peru chega a US\$ 9 bilhões, a da Colombia US $\$ 5,9$ bilhões, a da Bolívia R $\$ 2,5$ bilhões, enquanto a do Brasil está em US $\$ 1,4$ bilhão, considerando os recursos em carteira provenientes dos $2 \%$ dos depósitos a vista, tanto aqueles empregados em consumo, quanto para financiar atividades produtivas. Certamente que há diferenças no conceito de microcrédito entre esses países. No entanto, na Bolívia, por exemplo, as operações abaixo de US\$10 mil correspondiam a $45 \%$ de sua carteira de microcrédito, em junho de $2012^{94}$. Diante desses números, a pergunta que inevitavelmente ocorre é por que os sistemas bancários desses países conseguem prover crédito para quem não tem renda, enquanto no Brasil, o governo patina em intermináveis medidas provisórias e revisões legais?

\section{Gráfico 2. Carteira Ativa de Microcrédito do Peru, Colômbia, Bolívia e Brasil, 2001- 2011}

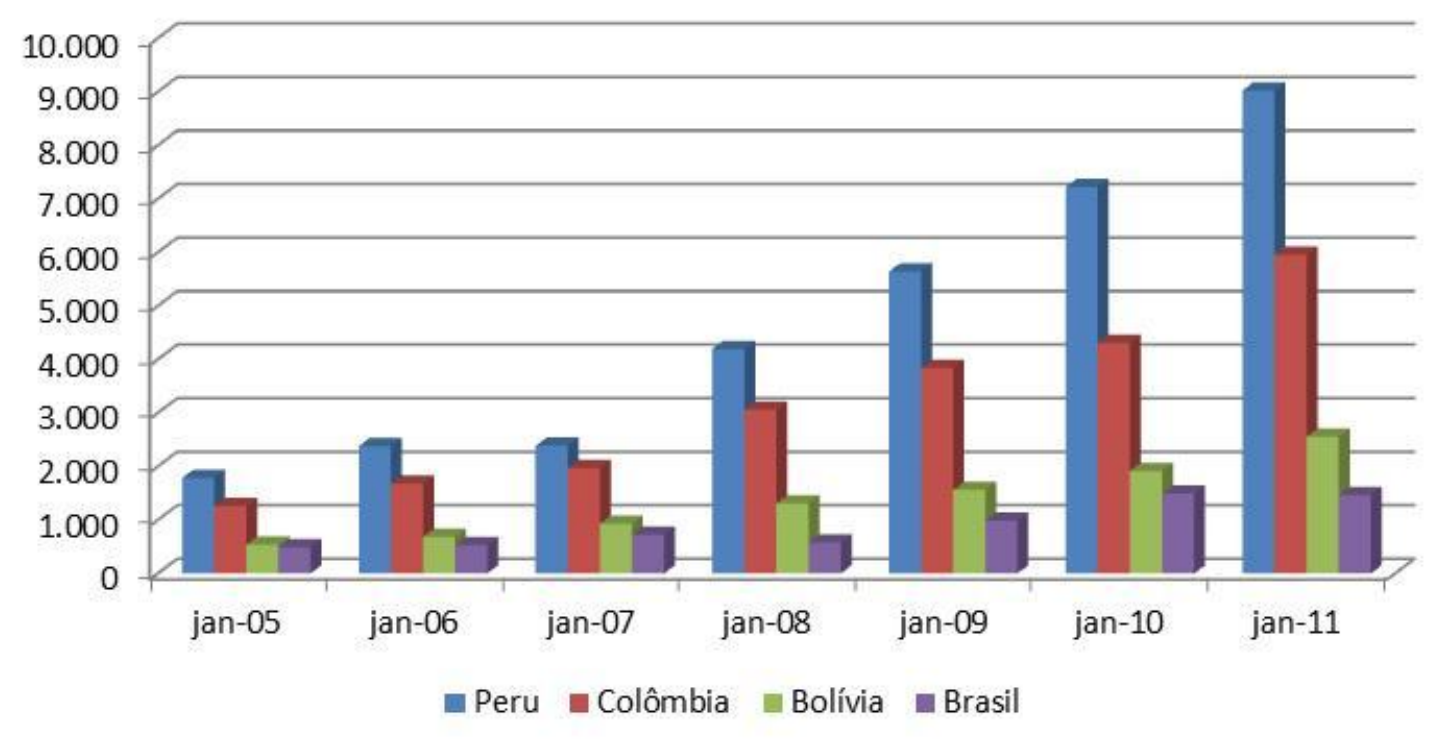

Fonte: Brasil - Bacen; Peru - ASOMIF; Colômbia - SFC; Bolívia - ASOFIN

\footnotetext{
${ }^{94}$ Cf. ASOFIN, Estratificacion em funcion del monto desembolsado de la cartera, por numero de clientes AL, 30/06/2012. Disponível em www.asofinbolivia.com/sp/financiera08.asp
} 
A estratégia em tornar os bancos tradicionais protagonistas das operações de microcrédito no Brasil destoa da experiência desenvolvida na América Latina, onde os principais atores foram as Ongs. Beatriz Marulanda (2006) diz que as experiências de sucesso com microcrédito no sistema financeiro tradicional são casos isolados e a participação desse setor tem sido baixa na América Latina. Argumenta que muitos bancos entraram no mercado de microfinanças certos de que a tecnologia bancária que possuíam não era apropriada. Por essa razão, separaram o portfólio de microcrédito do restante das outras operações.

"É difícil integrar as melhores práticas das operações de microcrédito em controlar risco e reduzir custos às operações dos bancos comerciais tradicionais. As instituições de microfinanças possuem uma estrutura salarial, sistemas de remuneração, de gestão de carteiras, de recuperação de crédito que diferem amplamente dos bancos tradicionais. Administração de empréstimos e os esforços de cobrança são também extremamente trabalhosos e difíceis, resultando na necessidade de altas taxas de juros, que dariam uma imagem aos bancos de serem muito caros" (Marulanda, 2006:91).

Em consequência dessas diferenças, a autora diz que os bancos comerciais desenvolveram modelos organizacionais diversos para alcançar 0 mercado de microcrédito. As soluções variam de acordo com o tamanho do banco e de seu compromisso com a questão da pobreza:

"Alguns bancos criaram novas divisões dentro de sua estrutura institucional. Outros estabeleceram subsidiária financeira ou subsidiária em serviços financeiros que atua como um canal de contato com microempreendedores. Alguns integraram as operações no próprio banco, outros formaram parcerias com ONGs" (idem).

Argumenta que para os grandes bancos o mais difícil é integrar o microcrédito na estrutura formal, pois possuem rígidas diretrizes, o que dificulta introduzir novos modelos de negócios. Além disso, a importância das pequenas operações de crédito nessas instituições é ofuscada pelo amplo volume das tradicionais, onde a capacidade administrativa e de recuperação de crédito estão concentradas. Por essa razão, na 
América Latina tem sido mais comuns os processos de upgruding ${ }^{95}$ que os de downscaling e os resultados também são melhores no primeiro que no segundo caso.

\section{O INTERESSE DOS BANCOS}

Embora o setor de microcrédito, numa análise rápida, pudesse representar para os bancos um novo nicho negocial, que possibilitasse diversificar portfólio de produtos e serviços, não se institucionalizou modelo de microcrédito capaz de gerar ganhos em escala e manter custos compatíveis com seus modelos de negócio. Hoje, o padrão adotado de microcrédito segue o desenvolvido por organizações sem fins lucrativos. Baseia-se na concessão assistida de crédito, realizada pelo agente de crédito que visita os empreendimentos e acompanha suas atividades, e utiliza sistemas de garantias alternativas, como o aval solidário. A operacionalização exige qualificação profissional específica para avaliar a viabilidade do empreendimento a ser financiado e orientar o empreendedor, qualificações que se distanciam daquelas típicas de um bancário.

Há, ainda, o custo em reunir e avaliar os vários tomadores de crédito que serão solidários no empréstimo e desenvolver tecnologia bancária para acompanhar os nanoempreendimentos (sistemas informatizados, critérios de análise de crédito específicos, base de dados etc.). Tudo isso significa para os bancos comerciais, que atuam com elevada alavancagem financeira, novos investimentos numa modalidade de crédito que, por suas próprias características, trabalha com margens reduzidas, valores pequenos de empréstimos e prazos curtos. Portanto, contraditoriamente, o microcrédito envolve custos e riscos maiores que as linhas de crédito tradicionais, e requer ganho em escala para seu pleno funcionamento e viabilização. Tais empecilhos tornam o mercado de microcrédito pouco atrativo para os bancos, levando-os a operar no limite dos incentivos ou regulamentações compulsórias.

Do ponto de vista das Ongs, o mercado de microcrédito pode ser atrativo, pois o seu objetivo não é maximizar resultados e minimizar situações de risco, mas zelar pela

\footnotetext{
${ }^{95}$ Upgrading refere-se ao processo em que informal ou semi-formal instituição de microfinança passa a ser regulada e supervisionada por entidades bancárias de seus países e torna-se parte do sistema financeiro formal (Cf. Beger, Otero e Schor: 2006: 38). Já downscaling corresponde ao movimento dos bancos comerciais e outras instituições financeiras para levar serviços financeiros à população de baixa renda ou sem comprovação de renda (Cf. Berger, 2006: 22).
} 
proteção social, a organização produtiva e a transformação social da comunidade assistida. Os resultados que desejam alcançar não são imediatos ou por produtividade, e esse posicionamento permite que as Ongs acompanhem com maior proximidade as potencialidades e os riscos das atividades financiadas. Já os bancos, mesmo quando lidam com operações de microcrédito, costumam empregar a metodologia tradicional de atendimento e de análise de crédito, a fim de viabilizar ganhos em escala. Tal estratégia negocial acaba sendo mais arriscada que a das Ongs, conforme ficou demonstrado nas crises econômicas que ocorreram na América Latina. As carteiras de crédito das IMFs sofreram menos impacto que das instituições bancárias tradicionais e se recuperaram mais rápido, demonstrando que aquelassouberam selecionar melhor seus clientes e os empreendimentos financiados (Cf. Berger, Otero e Schor, 2006:58).

Não é apenas no Peru, Bolívia e Colombia - países onde a experiência com microfinanças possui longa história - que as Ongs parecem se sair melhor que os bancos quando o assunto é microfinanças. Mesmo no caso brasileiro, que a legislação estabelece uma série de restrições às atividades das IMFs, as Oscips respondem por quase a metade da carteira dos bancos tradicionais do Programa Nacional de Microcrédito ${ }^{96}$ principal funding das operações de microcrédito voltadas para empreendimentos produtivos (cf. tabela 1).

Tabela 1. Carteira Ativa PNMPO por Constituição Jurídica no 2ำ trimestre de 2012

Constituição Jurídica

Agência de Fomento

Banco Cooperativo

Banco de Desenvolvimento

Inst. Financeira Operadora

Oscip

SCM

TOTAL
Valor da Carteira Ativa_30/06/2012

$26.746 .056,45$

$58.028 .337,74$

$1.350 .048 .985,52$

4 32.322.803,85

$209.520 .823,43$

$9.935 .815,08$

2.086.602.822,07
$\%$

$1,28 \%$

$2,78 \%$

$64,70 \%$

$20,72 \%$

$10,04 \%$

$0,48 \%$

$100,00 \%$

O desempenho das Oscips contrasta com os dos bancos principalmente quando se compara o porte dessas organizações. Das 103 Oscips identificadas pelo Sebrae e cadastradas para operar com o PNMPO, 42 possuem uma carteira menor que R\$ 2

\footnotetext{
${ }^{96}$ Fonte: MTE. Relatório de Dados do Programa de Microcrédito - $2^{0}$ Trimestre de 2012.
} 
milhões (cf. gráfico 3). Sem falar que elas não têm a mesma estrutura de análise de crédito, tecnologia para processar as informações de clientes, rede de atendimento, enfim, trabalham com estrutura física e de pessoal muito mais frágil e, mesmo assim, conseguem atingir a metade do resultado de todos os bancos que operam no País.

\section{Gráfico 3 - Carteira de Crédito das Oscips}

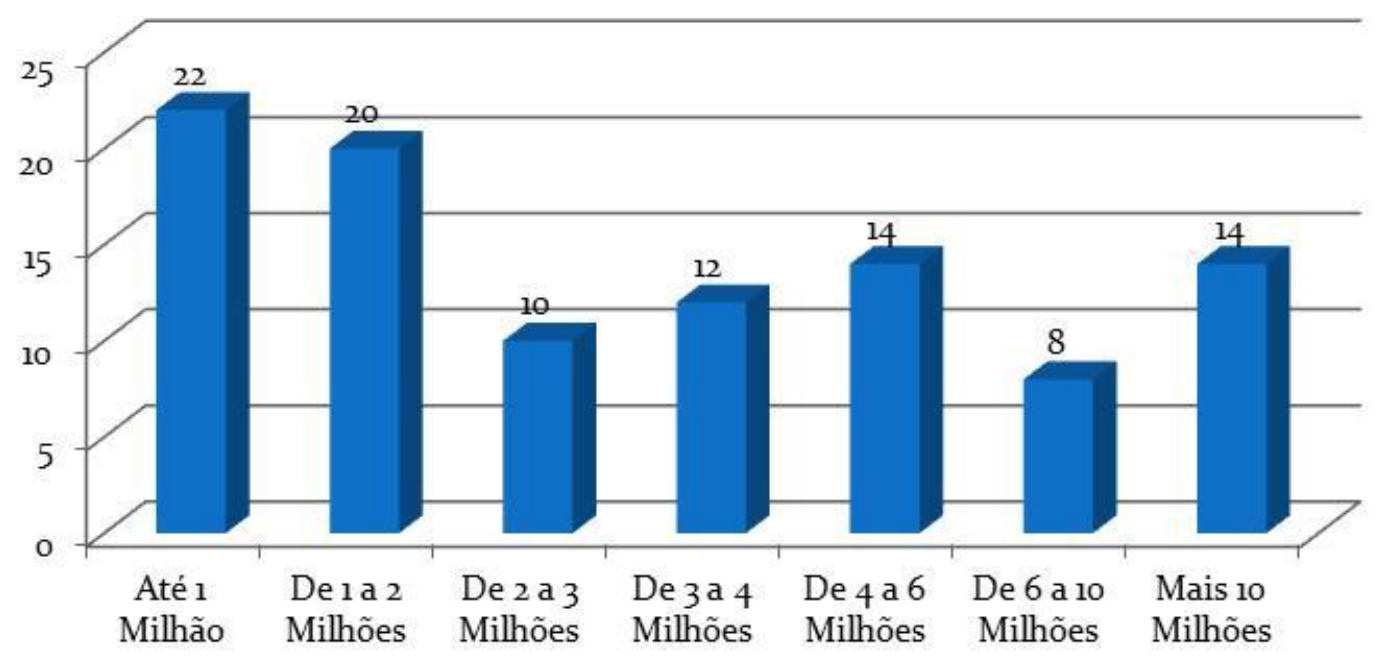

Fonte: Sebrae

A razão pela qual as Ongs brasileiras não caminharam para se constituir em bancos especializados em microfinanças, provavelmente, se deve as restrições legais que dificultam a expansão de suas atividades e a diversificação de portfólio de produtos e serviços. Não apenas as Ongs estão limitadas em suas operações, como também as SCM, conforme descrito antes. De maneira geral, as IMFs estão impossibilitadas de captar recursos no mercado, trabalham essencialmente com capital próprio ou proveniente do setor financeiro. Podem emprestar somente para empreendimentos produtivos, além de outras limitações fixadas em lei, como taxa de juros, valor máximo dos empréstimos e as características dos tomadores finais.

Pesquisa encomendada pelo Ministério do Trabalho e Emprego ${ }^{97}$ sobre o marco legal do setor de microfinanças no Brasil concluiu que as normas que o regulam criaram "obrigações burocráticas e artificiais às pessoas jurídicas que atuam na atividade" sem

\footnotetext{
${ }^{97}$ Ministério do Trabalho e Emprego, Programa Nacional de Microcrédito Produtivo Orientado. Diagnóstico do Marco Legal das Microfinanças no Brasil, 2008, Brasília - DF.
} 
Ihes garantir proteção ou serem necessárias. Contribuem apenas para "limitar e desincentivar" as iniciativas no campo microfinanceiro por limitar artificialmente produtos, valores, juros e fixar métodos de atuação.

A justificativa do Banco Central e BNDES para não fazer alteração na legislação que possibilitaria às Ongs evoluírem para instituições bancárias é a fragilidade de sua estrutura de funcionamento:baixa capacidade de investimento, de acessar fatores essenciais ao seu desenvolvimento, como tecnologia de informação, assistência técnica, financeira, jurídica e contábil, entre outros motivos. O BNDES reconhece que "a experiência internacional mostra que a migração de entidade não regulada para regulada, com direito à captação de poupança, foi essencial para a ampliação da capacidade de atendimento das organizações de microcrédito, e sem perder o foco no tomador de baixa renda" (Coelho e Prandini, 2009:46). No entanto, argumenta que essa alteração no marco legal não é viável, pois "as Oscips além de problemas de gestão, dispõem de poucos recursos e possui reduzida carteira de clientes, insuficiente para sua sustentação financeira. Até mesmo as de maior porte podem ser consideradas pequenas, quando comparadas a instituições financeiras que operam com microcrédito na América Latina" (Coutinho, Ambrozio, Sant'ana, Montoro, 2009:59).

Forma-se assim um círculo vicioso, onde a legislação não muda porque as IMFs não estão estruturadas para assumir responsabilidades como instituições bancárias, e as IMFs não se estruturam, porque não encontram condições legais paradiversificar seu portfólio de produtos e ampliar carteira de clientes.

Esses impedimentos legais, que constrangem a atuação das IMFs no Brasil, não foram observados em outros países da América Latina, o que em parte explica o melhor resultado alcançado. Segundo Berger, Otero e Schor (2006), o sistema de microfinanças na América Latina contou com a assistência de Ongs internacionais na estruturação de suas atividades, provendo funding para o início das operações, tecnologia bancária e técnicas de gestão financeira e administrativa. Entre as Ongs internacionais que tiveram presença na América Latina, destacam-se a ACCION International (Bolívia, Colombia, México e Peru) e IPC (El Salvador e Nicarágua). O marco regulatório também foi importante para o fortalecimento das IMFs, pois permitiu que as Ongs evoluíssem para instituições reguladas, podendo captar poupança e depósitos, e chegassem à situação de bancos de varejo, oferecendo uma variedade de produtos financeiros. 
Tal processo permitiu as Ongs acumular conhecimento sobre a atividade financeira, a medida que os negócios de seus clientes se desenvolviam e passavam a demandar maior complexidade e diversidade de produtos e serviços. Inicialmente, as Ongs ofereciam apenas microcrédito, quando sua carteira foi se tornando mais robusta e sustentável, passaram a diversificar serviços, atendendo as novas demandas que surgiam dos seus clientes (cartão de crédito, seguros, previdência, gestão de folha de pagamento etc.). As Ongs cresceram economicamente junto com os empreendedores, num processo paralelo de fidelização e aprendizagem. Conforme Berger, Otero e Schor, os principais fatores que incentivaram as Ongs a tornarem-se instituições bancárias foram: a possibilidade de captar depósitos dos consumidores e acesso ao mercado de capitais. Ao passarem a condição de instituições financeiras reguladas, as Ongs conquistaram maior credibilidade e confiança dos clientes, puderam captar depósitos de consumidores e interbancários e tomar empréstimos de fontes internacionais. Assim, aumentaram o funding para suas operações de crédito e alavancaram novos negócios.

No Brasil, o marco legal colocou tantas limitações às atividades das IMFs, que o apoio de Ongs internacionais não produziu o mesmo resultado. A presença dos bancos não substituiu o papel que as Ongs internacionais tiveram nos demais países da América Latina. Ao contrário, os bancosagiram de forma predatória em relaçãoà carteira de clientes das IMFs. Quando entraram no mercado de microcrédito, contrataram os agentes das Oscips, oferecendo salários e ganhos melhores. Esses levaram os clientes que conheciam para operar com os bancos (cf. Ministério do Trabalho, 2008:47).

\section{CONCLUSÃO}

A estratégia do governo, a partir de 2003, foi incentivar a participação dos bancos para ampliar o volume de contratações de microcrédito, já que o desempenho das Oscips e SCMs sinalizava que não cumpririam o papel que o governo colocava para o crédito em sua política econômica. Na nova gestão, microcrédito perde o caráter de programa social e passa a ser assunto do Ministério da Fazenda, ferramenta chave para fortalecer mercado interno e incentivar o consumo de massa. Por essa razão, o governo modifica o marco legal e, através da Medida Provisória n. 122 de 2003 (Resolução 3.109 de 2003), elevando os bancos ao status protagonistas da política de microcrédito. 
A análise histórica demonstrou que as mudanças na legislação não conseguiram para garantir a participação dos bancos, tampouco ampliou a presença das SCMs e Oscips. Apesar de toda estrutura tecnológica, capilaridade nacional, volume de fundings disponível e outros elementos a seu favor, o mercado de microfinanças parece não ser um bom negócio para as instituições bancárias. A hipótese levantada é a de que esse mercado possui características muito específicas, que o diferenciam do padrão de atendimento bancário: tecnologia de análise de crédito diferenciada, qualificação específica para seus agentes, trabalha com prazos curtos e volumes de empréstimos pequenos, enfim possui custos maiores e margens estreitas, e, por essas razões, não são atrativos ao setor bancário. O microcrédito só é atrativo para os Bancos quando possibilita ganhos em escala, no entanto, os empreendimentos financiados exigem acompanhamento individualizado. Soma-se, ainda, o fato de que os grandes bancos possuem carteiras de clientes que possibilitam operar com margens de lucro maiores que as do microcrédito.

Já as Ongs, atuam segundo outra racionalidade, trabalham com vistas a resultados a médio e longo prazos, com foco não apenas em ganhos econômicos, mas também sociais. Como sua carteira de clientes é pequena, aceitam operar com margens menores e podem acompanhar o desenvolvimento dos negócios financiados. Para as Ongs, vale a pena gastar tempo e recursos para selecionar clientes cujos empreendimentos demonstram ser rentáveis e sustentáveis.

Por essa razão, para expandir as operações de microcrédito, o governo deveria investir na estruturação das IMFs, adotando estratégia semelhante a das Ongs internacionais que entraram em mercados de outros países da América Latina, ou seja, financiando e promovendo qualificação técnica, tecnologia bancária e informatização. Também seriam fundamentais mudanças no marco legal de microfinanças que possibilitassem as IMFs descrever a mesma trajetória assistida em outros países da América Latina: saírem de Ongs para instituições financeiras reguladas e chegarem a bancos especializados em microfinanças.

Observa-se no Brasil um circulo vicioso. Os órgãos reguladores e provedores de funding para as operações de microcrédito não permitem que as Ongs diversifiquem seus serviços, pois alegam que elas possuem baixa estruturação. Já as Ongs não se estruturam, pois não encontram espaço para ampliar sua atuação em razão das 
limitações legais. Enquanto isso, os bancos não entram no mercado de microfinanças que para eles parece pouco atrativo. Diante desta configuração, permanece uma parcela da população brasileira excluída do mercado financeiro, sem acesso a crédito e outros serviços bancários, que poderia contribuir para aumentar nível de renda e criar oportunidades de emprego.

Demonstra-se assim que configuração institucional é variável importante para estudar mercado. Se fossem consideradas apenas variáveis econômicas para interpretar o comportamento do mercado de microfinanças no Brasil - tais como demanda existente, capital tecnológico do setor bancário e índices de crescimento econômico - natural seria que o Brasil saísse à frente de outros países da América Latina em razão do desempenho de sua economia e da solidez de seu sistema bancário. No entanto, o resultado é o oposto do esperado. Por isso, supõe-se que o marco jurídico que regula a atividade de microfinanças nesses países, em conjunto com outros fatores como a presença de Ongs internacionais, criou um ambiente propício para o crescimento das IMFs.

\section{REFERÊNCIAS}

ABRAMOVAY, Ricardo. 2004. Entre Deus e o Diabo: mercados e interação humana nas Ciências Sociais. Tempo Social, Revista de Sociologia da USP, v. 16, n.2.

ANTEAG - Associação Nacional dos Trabalhadores e Empresa de Autogestão e Participação Acionária (orgs). 2009. Atlas da Economia Solidária no Brasil 2005 a 2007. São Paulo, Todos os Bichos.

Banco Central do Brasil. Relatório de Inclusão Financeira, Brasília, BCB, 2010.

Banco Central do Brasil. Relatório de Inclusão Financeira, n. 2, Brasília, BCB, 2011.

BARONE, Francisco Marcelo e SADER, Emir. "Acesso ao crédito no Brasil: evolução e perspectiva". Revista de Administração Pública, Rio de Janeiro 42(6): 1249-67, nov./dez. 2008.

BARONE, Francisco Marcelo; LIMA, Paulo Fernando; DANTAS, Valdi e REZENDE,Valéria. 2002. Introdução ao Microcrédito. Brasília, Conselho da Comunidade Solidária.

BERGER, Marguerite, OTERO e SCHOR, Gabriel. 2006. "Pioneers in theCommercializationofMicrofinance". In: An Inside View of Latin American Microfinance, Inter-American Development Bank, Washington, EUA. 
BERGER, Margerite. 2006. "The Latin American Modelo of Microfinance”. In: An Inside View of Latin American Microfinance, Inter-American Development Bank, Washington, EUA.

BRASIL. Presidência da República. Conselho da Comunidade Solidária. Interlocução Política do Conselho da Comunidade Solidária. Atuação do Conselho da Comunidade Solidária para a Expansão do Microcrédito no Brasil 1995 - 2002, Brasília, 2002

COELHO, J. Max Brito e PRANDINI, Edmar Roberto. 2009. Programa Nacional de Microcrédito Produtivo e Orientado: conquistas e Desafios. In: FELTRIM, Luiz Edson; VENTURA, Elvira Cruvinel Ferreira, DODL, Alessandra von Borwski. Perspectivas e Desafios para Inclusão Financeira no Brasil: visão de diferentes atores. Brasília, Banco Central do Brasil

COUTINHO, Luciano Galvão; AMBROZIO, Antônio Marcos Hoelz Pinto; SANT'ANA, André Albuquerque e MONTORO, Guilherme Castanho Franco. 2009. Inclusão Financeira no Brasil: o papel do BNDES. In: FELTRIM, Luiz Edson; VENTURA, Elvira Cruvinel Ferreira, DODL, Alessandra Von Borwski. Perspectivas e Desafios para Inclusão Financeira no Brasil: visão de diferentes atores. Brasília, Banco Central do Brasil.

FALABELLA, Pedro e MONTEIRO, Silvana. 2009. A Responsabilidade dos Bancos de Desenvolvimento e das Agências de Fomento com o Crédito Inclusivo. In: FELTRIM, Luiz Edson; VENTURA, Elvira Cruvinel Ferreira, DODL, Alessandra vonBorwski. Perspectivas e Desafios para Inclusão Financeira no Brasil: visão de diferentes atores. Brasília, Banco Central do Brasil.

FELTRIM, Luiz Edson; VENTURA, Elvira Cruvinel Ferreira; DODL, Alessandra von Borowski. Introdução. 2009. In: FELTRIM, Luiz Edson; VENTURA, Elvira Cruvinel Ferreira, DODL, Alessandra vonBorwski. Perspectivas e Desafios para Inclusão Financeira no Brasil: visão de diferentes atores. Brasília, Banco Central do Brasil

FLIGSTEIN, Neil e DAUTER, Luke. 2007. "The Sociology of Markets". The Annual Review of Sociology, 33:105-128

GRANOVETTER, Mark. 1985. Economic Action and Social Structure: the Problem of the Embeddedness. The American Journal of Sociology, vl. 91, n. 3, p. 481-510, nov.

Theory, vol. 1, 201-233.

1983. The Strength of Weak Ties: a Network Theory Revisited. Sociology

LEVORATO, Wilson Roberto. "Microfinanças e o Sistema bancário brasileiro". 2009. In: FELTRIM, Luiz Edson; VENTURA, Elvira Cruvinel Ferreira, DODL, Alessandra vonBorwski. Perspectivas e Desafios para inclusão financeiro no Brasil: visão de diferentes atores. Brasília, Banco Central do Brasil.

MARULANDA, Beatriz. 2006. "Downscaling: Moving Latin American Banks into Microfinance”. In Berger, Marguerite; Goldmark, Lara; Sanabria, Tomás Miller (orgs), An 
Inside View of Latin American Microfinance, Inter-American Development Bank, Washington, EUA.

MEYER, John W. and ROWAN, Brian. 1977. Institutionalized Organizations: Formal Structure as Myth and Ceremony. American Journal of Sociology, 83 (2): 340-63.

Ministério do Desenvolvimento Social, Plano Brasil Sem Miséria.

Ministério da Fazenda, Secretaria de Política Econômica. 2004. Reformas Microeconômicas e Crescimento de Longo Prazo, Brasília - DF.

Ministério do Trabalho e Emprego. 2008. Diagnóstico do Marco Legal das Microfinanças no Brasil. Brasília - DF.

Ministério do Trabalho e Emprego, Programa Nacional de Microcrédito Produtivo e Orientado. Relatório de Dados do Programa de Microcrédito, $2^{\circ}$ Trimestre de 2012. Disponível em http://portal.mte.gov.br/pnmpo/banco-de-dados.htm

NEE, Victor. 2001. "Sources of the New Institutionalism". In: BRINTON, Mary C. e

NEE, Victor (orgs.), The New Institutionalism in Sociology, Califórnia, Stanford University Press.

NETO, Rubens de Andrade e PINTO, Edson Luiz de Paula. As Sociedades de Crédito ao Microempreendedor _ Origem Desenvolvimento e Futuro. VI Seminário Banco Central sobre Microfinanças, Porto Alegre, junho/2007. Disponível in http://www.bcb.gov.br/pre/microFinancas/arquivos/horario arquivos/trab 44.pdf

NETO, Rubens de Andrade. "Sociedades de Crédito ao Microempreendedor e à Empresa de Pequeno Porte: história e perspectiva". 2009. In: FELTRIM, Luiz Edson; VENTURA, Elvira Cruvinel Ferreira, DODL, Alessandra Von Borwski. Perspectivas e Desafios para Inclusão Financeira no Brasil: visão de diferentes atores. Brasília, Banco Central do Brasil

NORTH, Douglass C. Institutions, Institutional Change and Economic Performance. Cambridge, Cambridge University Press, 2004.

PEREIRA, Almir da Costa; MROSS, Cristiano; ALVES, José Caetano Lavorato e AGUIAR, Luiz José Bueno. 2009. Massificação das Microfinanças no Brasil - Análise e proposições. In: FELTRIM, Luiz Edson; VENTURA, Elvira Cruvinel Ferreira, DODL, Alessandra Von Borwski. Perspectivas e Desafios para inclusão financeiro no Brasil: visão de diferentes atores. Brasília, Banco Central do Brasil.

POWELL, Walter W. e DIMAGGIO, Paul J. Introducción. 1999. In: .(org). El Nuevo Institucionalismo en el Análisisis Organizacional. México, Universidade Autónoma del Estado de Mexico. 
1983. The Iron Cage Revisited: Institutional Isomorphism and Collective Rationality in Organizational Fields. In: American Sociological Review, vol. 48, p. 147160 , abr.

SEN, Amartya. 2010. Desenvolvimento como Liberdade. São Paulo, Companhia das Letras.

Serviço Brasileiro de Apoio às Micro e Pequenas Empresas. 2012. Perfil das Instituições de Microfinanças (OSCIP) no Brasil, Brasília - DF.

SOARES, Marden Marques e SOBRINHO, Abelardo Duarte de Melo. 2008. Microfinanças: o papel do Banco Central do Brasil e a importância do Cooperativismo de Crédito. Brasília, Banco Central do Brasil.

SWEDBERG, Richard. 1994. "Markets as social structures". In: SWEDBERG, Richard and SMELSER, Neil J. The handbook of economic sociology, Princeton/Nova York, Princeton University Press/Russel Sage Foundation. 